\title{
An Analysis on the Temporal Patterns of Heat Island Effect in Kaohsiung
}

\author{
Yu-Long Chao
}

\begin{abstract}
According to the hourly temperature data from the database of Environmental Protection Administration, this study compared the temperature in January and July 2011 in three downtown locations with those in three suburban locations. Possible causes of temperature differences between downtown and suburban locations were discussed; in particular the temperature rise resulted from economic activities such as the traffic in rush hours and waste heat of air conditioners of buildings. The temperature records were analyzed based on hours and days and hence day patterns and week patterns of temperature differences between downtown and suburban were obtained. Results revealed that temperature change was directly influenced by surrounding physical environment but certain patterns of temperature differences still emerged. With respect to day patterns, temperature differences reached peaks around 2 PM and were in greater variances in summer than in winter. For week patterns, by contrasting weekday temperature with weekend temperature, it was found that cycles of temperature peaks probably caused by economic activities were obvious during weekdays in winter. Downtown was also found warmer than suburban at winter nights, consistent with the phenomenon of heat island effect. Practical implications for urban environmental management were discussed.
\end{abstract}

Index Terms-Heat island effect, time series, urbanization.

\section{INTRODUCTION}

The phenomenon of heat island effect is characterized by higher air temperatures in dense urban areas than the temperatures of surrounding suburban areas [1]. Occurring in every town and city, it is the most obvious climatic manifestation of urbanization [2] and has spatial and temporal variation [1]. Human activities, especially economic ones, should be influential in the formation of the heat island effect in densely populated cities. In this study, the effect of economic activities is investigated with multiple comparisons between downtown and suburban temperature time series. With the hourly temperature records of observation stations in Kaohsiung, the second largest city in Taiwan, it aims to present the temporal pattern of temperature difference between downtown and suburban stations that reflects clearly an association with the cycles of daily economic activities.

Factors influencing heat island effect ranges from climate, topography, land use, to waste heat of various sources have been studied [3]-[5]. Among these factors, anthropogenic heat emitted from stationary and mobile sources relates to business operations in which boilers and engines of vehicles burn fuels and air conditioners discharge heat. This motivates the

Manuscript received May 20, 2015; revised August 4, 2015.

Yu-Long Chao is with the National Kaohsiung First University of Science and Technology, Taiwan (e-mail: chaoyulong@gmail.com). investigation of whether intensified heat island effect can be observed around rush hours. Besides, daily patterns of temperature difference between downtown and suburban stations in summer and winter are also presented in this study to further examine whether they are consistent with typical patterns of heat island effect. As cities get hotter, citizens suffer from unbearable living environment as well as vicious cycle of more air-conditioning and hotter urban air. Realizing how we contribute to the hotter cities should be informative for us to learn how to cool the cities.

\section{METHOD}

\section{A. Location}

In the south-west of Taiwan, Kaohsiung covers 2,947 km2 with a population of approximately 2.7 million. The latitude of Kaohsiung is one degree to the south of the Tropic of Cancer with monthly mean temperatures between 20 and $29^{\circ} \mathrm{C}$ and an average annual rainfall around 1,800 $\mathrm{mm}$ [6]. The Environmental Protection Administration (EPA) set up across the city a total of 16 air quality monitoring stations from which six are selected and grouped into nine downtown-suburban pairs according to their levels of urbanization (Table I).

TABLE I: THE SELECTED MONITORING STATIONS

\begin{tabular}{|c|c|}
\hline Downtown & Suburban \\
\hline $\begin{array}{l}\text { Fengshan } \\
\left(22^{\circ} 37^{\prime} 38^{\prime \prime} \mathrm{N}, 120^{\circ} 21^{\prime} 29^{\prime \prime} \mathrm{E}\right)\end{array}$ & $\begin{array}{l}\text { Ciaotou } \\
\left(22^{\circ} 45^{\prime} 27^{\prime \prime} \mathrm{N}, 120^{\circ} 18^{\prime} 20^{\prime \prime} \mathrm{E}\right)\end{array}$ \\
\hline $\begin{array}{l}\text { Cianjin } \\
\left(22^{\circ} 37^{\prime} 57^{\prime} \mathrm{N}, 120^{\circ} 17^{\prime} 17^{\prime} \mathrm{E}\right)\end{array}$ & $\begin{array}{l}\text { Daliau } \\
\left(22^{\circ} 33^{\prime} 57^{\prime \prime} \mathrm{N}, 120^{\circ} 25^{\prime} 30^{\prime \prime} \mathrm{E}\right)\end{array}$ \\
\hline $\begin{array}{l}\text { Fuhsin } \\
\left(22^{\circ} 36^{\prime} 31^{\prime \prime}, 120^{\circ} 18^{\prime} 43^{\prime \prime} \mathrm{E}\right)\end{array}$ & $\begin{array}{l}\text { Linyuan } \\
\left(22^{\circ} 28^{\prime} 46^{\prime \prime} \mathrm{N}, 120^{\circ} 24^{\prime} 42^{\prime \prime} \mathrm{E}\right)\end{array}$ \\
\hline
\end{tabular}

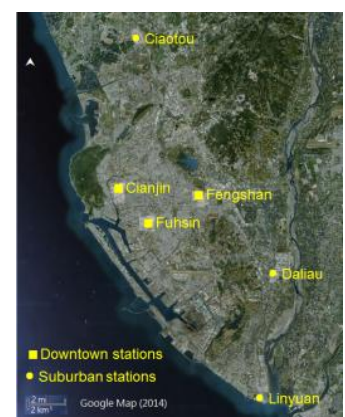

Fig. 1. Distribution of selected monitoring stations.

\section{B. Data}

The Air Quality Monitoring Web of EPA [7] offers not only air quality records but also basic meteorological records such as ambient temperature, rainfall, and wind direction that monitoring stations recorded hourly. For the analytic purpose 
of this study, the temperature data of the six monitoring stations downloaded from the web include the hourly temperature records in January and July 2011 as winter and summer data respectively.

\section{Analysis}

Pairing a downtown station with a suburban station from the selected stations yields nine downtown-suburban station pairs for the comparison of their temperature records. With Microsoft Excel as the analytic software, temperature differences between the downtown and the suburban station for each pair of stations are calculated and plotted. These data on temperature differences are further processed and analyzed on the following two bases:

\section{1) 24-hour pattern on weekdays}

There are 21 weekdays in January, and July as well, 2011. Take 9 AM for example, there are 21 temperature differences at $9 \mathrm{AM}$ and hence the mean and standard deviation (SD) of these temperature differences can be obtained for 9 AM. Likewise, for each of the rest 23 hours in a day, the means and SDs of these temperature differences can be obtained. As a result, a plot of three time series curves for each downtown-suburban pair can be generated (See Fig. 4 for example). These curves are:

- 24-hour mean + SD temperature difference curve

- 24-hour mean temperature difference curve

- 24-hour mean - SD temperature difference curve

Each downtown-suburban pair has two temperature difference plots: January plot and July plot. Since there are nine downtown-suburban pairs, a total of 18 plots are yielded.

\section{2) Seven-day pattern in weeks}

There are four weeks in January, and July as well, 2011. Take 9 AM on Monday for example, there are four temperature differences at $9 \mathrm{AM}$ on four Mondays respectively and hence the maximum, mean, and minimum temperature difference can be obtained for 9 AM on Mondays Likewise, for each of the rest 23 hours in each day of a week, the maximum, minimum, and mean temperature difference can be obtained. As a result, a plot of three time series curves for each downtown-suburban pair can be generated (See Figs. 6 to 8 ). These curves are:

- seven-day maximum temperature difference curve

- seven-day mean temperature difference curve

- seven-day minimum temperature difference curve

Likewise, each downtown-suburban pair has two temperature difference plots: January plot and July plot. Nine downtown-suburban pairs yield a total of 18 plots.

The subtraction algorithm applied for all of the above temperature differences is downtown temperature minus suburban temperature. Therefore, a segment of a curve that is above zero line in a plot indicates that downtown temperature is higher than suburban temperature in the period to which that segment corresponds.

\section{RESULTS AND DISCUSSION}

\section{A. Overall Temperature Variations}

The hourly temperature data of all six monitoring stations range between $10^{\circ} \mathrm{C}$ and $25^{\circ} \mathrm{C}$ in January and between $25^{\circ} \mathrm{C}$ and $36^{\circ} \mathrm{C}$ in July 2011. Curves in the temperature plots of all these stations present prominent daily cycles as exemplified by Fig. 2 and Fig. 3. Due to limited space, only a few of total plots are displayed here. Although downtown temperature curves and suburban ones are almost identical in this daily cyclic movement, temporal differences could emerge in further analysis on a weekly or 24-hour basis.

\section{B. 24-Hour Pattern on Weekdays}

Among the resultant 18 temperature difference plots, nine January plots and nine July plots, a few present a convex pattern with a rising temperature difference curve around noon, indicating even higher downtown temperature than suburban temperature then (Fig. 4 for example).

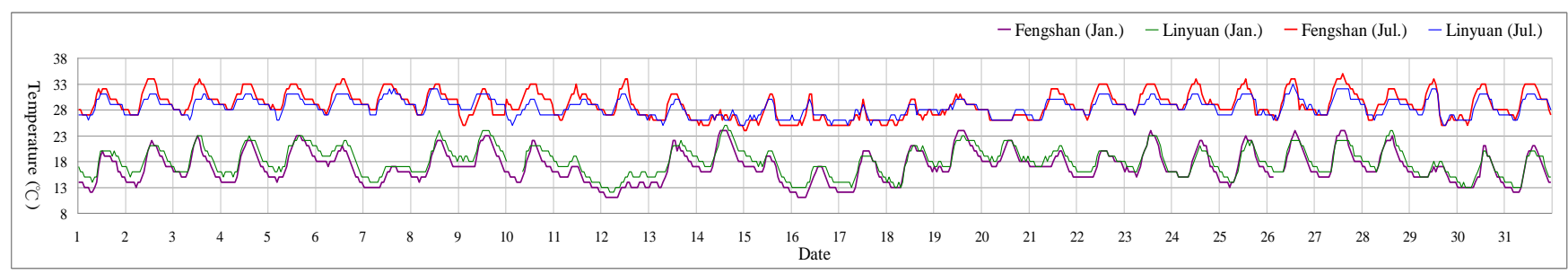

Fig. 2. The hourly temperature data of Fengshan and Linyuan stations.

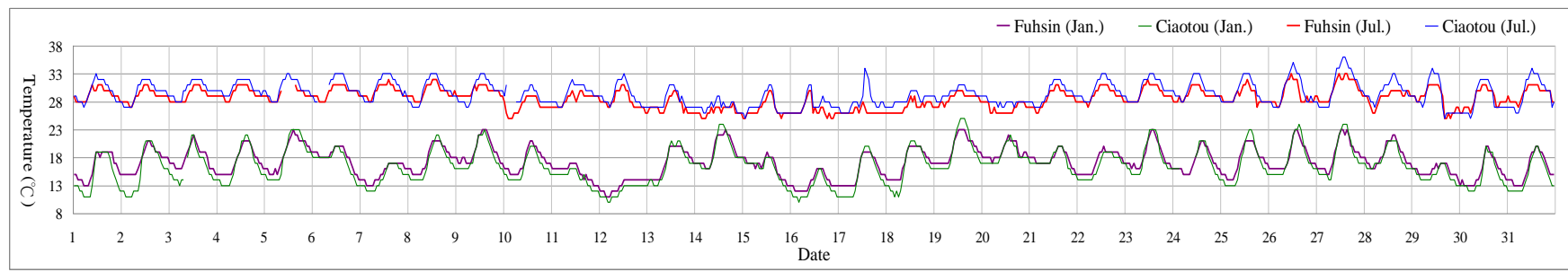

Fig. 3. The hourly temperature data of Fuhsin and Ciaotou stations.

Conversely, a few plots exhibit a concave pattern such as that in Fig. 5 with a plunging temperature difference curve around noon, reflecting even lower downtown temperature than suburban temperature then. This is consistent with Lin et al's finding of cool island effect in Kaohsiung around noon and is explained by greater heat capacity of downtown ground 
surface than that of suburban ground surface [8]. Water plays an important role in this regard and it necessitates the investigation on the distribution of water bodies as well as the water content of surface soils surrounding monitoring stations. Indeed, some monitoring stations locate in urban parks where surface soils of densely-vegetated land are more frequently and regularly watered than the surface soils of sparsely-vegetated land surrounding some monitoring stations in suburban areas.

Temperature differences of some downtown-suburban pairs vary greatly with time during a day. In Fig. 5(a), as the larger standard deviations (SD) during the period between 13 and 15 o'clock indicate, temperature differences between Fuhsin station and Ciaotou station have greater variance then than those during other periods of a day have. On one hand, this could be a result of the intense solar radiation then absorbed by the environment surrounding the stations with different heat capacity. On the other hand, it could be due to diverse local weather between stations. It is more likely in the afternoon that it rains at one station while it is sunny at the other station than it is in the morning or at night.
A comparison between the movement of mean temperature difference in January and that in July reveals that mean temperature difference reaches maximum later around 14 o'clock (2 PM) in January while earlier around 13 o'clock (1 $\mathrm{PM}$ ) in July. This lag of about one hour in maximum downtown-suburban temperature difference is a result of seasonal difference as the Sun heats up the Earth's surface more quickly in summer than in winter. It is found, from an overview on both the 24-hour plots and the seven-day plots in the following section, that the magnitude of downtown-suburban temperature difference is larger around noon and in July compared with that in other time of a day and in January, respectively. The finding is relevant with that the heat island effect in Taiwan is more pronounced in summer [9]. Solar radiation should be the major driver for the great rises and falls in temperature around noon as well as in summer. In the inspection on the influence of urban economic activities, no evidence of rush hour effects was observed in these 24-hour plots in that there are no drastic curve changes around 9 AM and 5 PM.

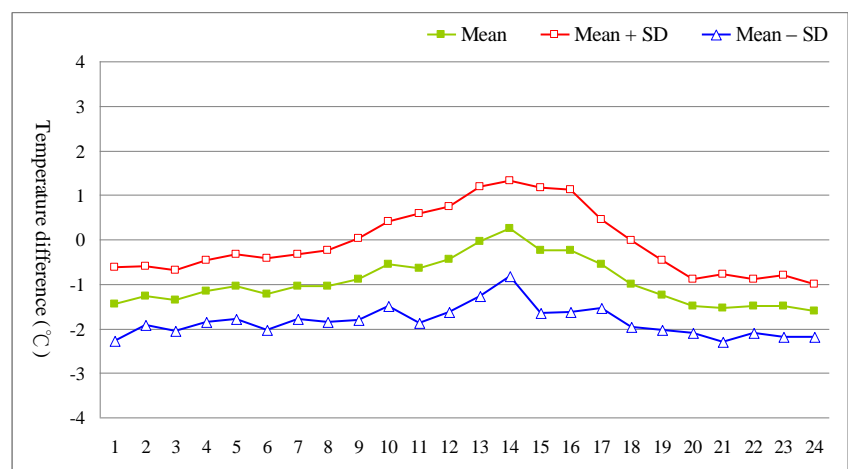

(a) January

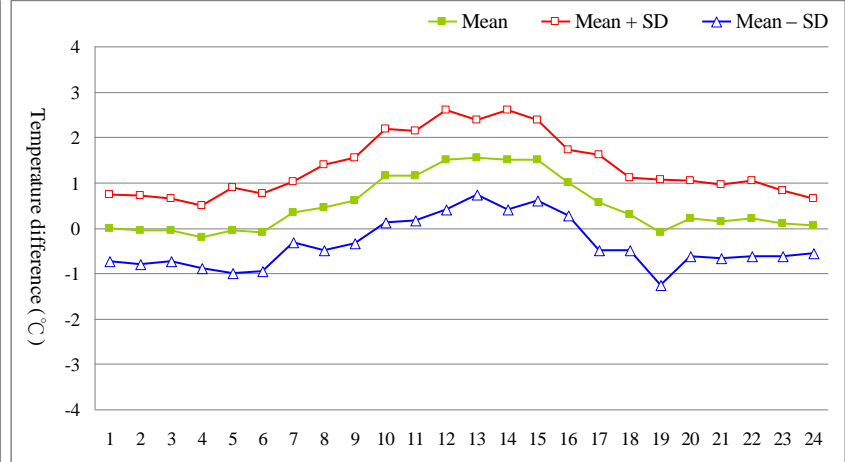

(b) July

Fig. 4. The 24-hour temperature difference between Fengshan-Linyuan stations on weekdays.

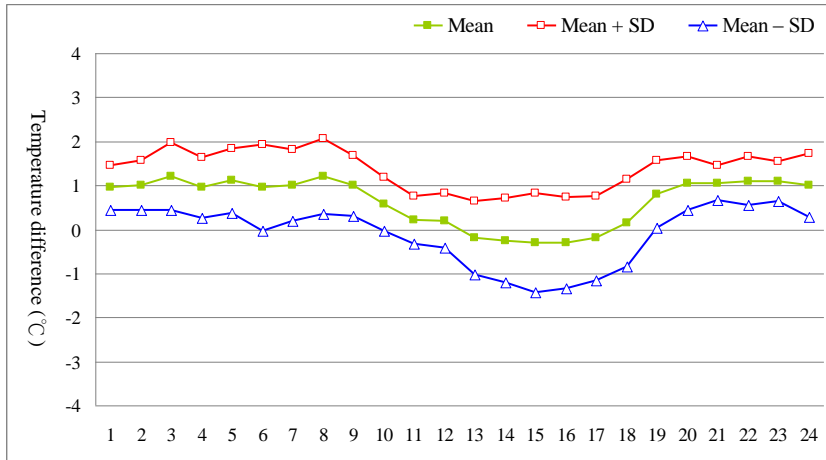

(a) January

Fig. 5. The 24-hour temperature difference between Fuhsin-Ciaotou stations on weekdays.

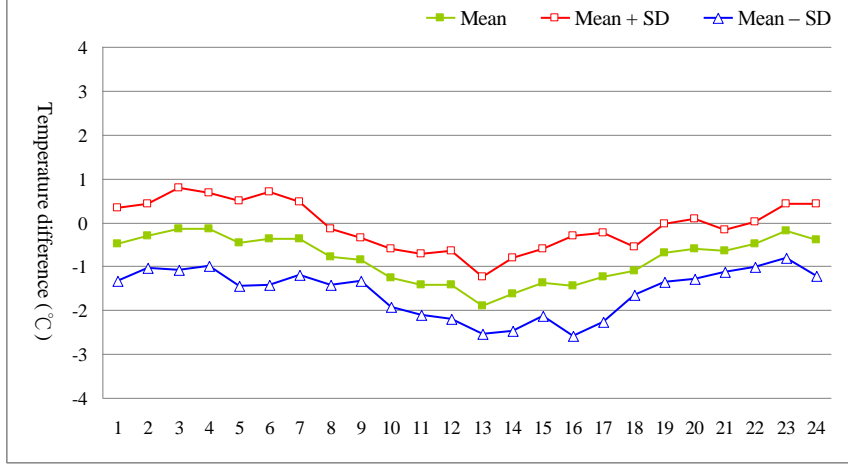

(b) July

\section{Seven-Day Pattern in Weeks}

The inspection on this pattern of downtown-suburban temperature difference is to identify the obvious inconsistency between weekday cyclic curves and weekend curves. Two plots (Fig. 6 and Fig. 7) of seven-day temperature difference curves are identified as reflective of general business schedule, working on weekdays and taking weekends off. The cycles of temperature difference curves Monday through Friday seem to disappear or fade on weekends. It is speculated that most business activities which release heat to urban environment cease on weekends, causing downtown temperature being no more higher than suburban temperature. This is justifiable since other non-human factors such as topography and weather condition should not always stop working on weekends. This striking pattern also exists in plots of temperature difference between two stations that both are classified as suburban stations, i.e., Daliau and Linyuan (Fig. 7). This could be due to the least economic activities in the surrounding areas of Linyuan station, suggesting its potential function as a baseline station.

Such a weekly cycle of temperature variations is also found 
in Melbourne and the role of anthropogenic heat release was studied [10]. It is also found that this pattern stands out in January plots rather than July plots. As a comparison with January, Fig. 8 presents no significant difference in curve movement between weekdays and weekends in July for the same pair of station. The temperature rises caused by heat-releasing business activities seem more detectable in a cooler environment in winter. While in summer, the effect of solar radiation should overwhelm the effect of heat released from business activities on both weekdays and weekends.

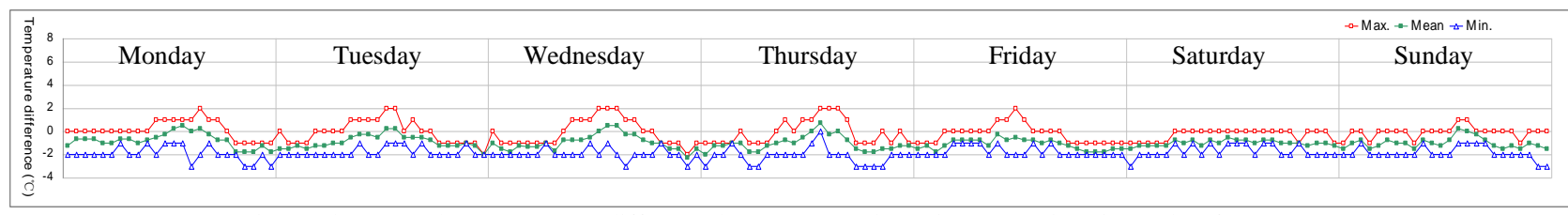

Fig. 6. The seven-day temperature difference between Fengshan-Linyuan stations in weeks of January.

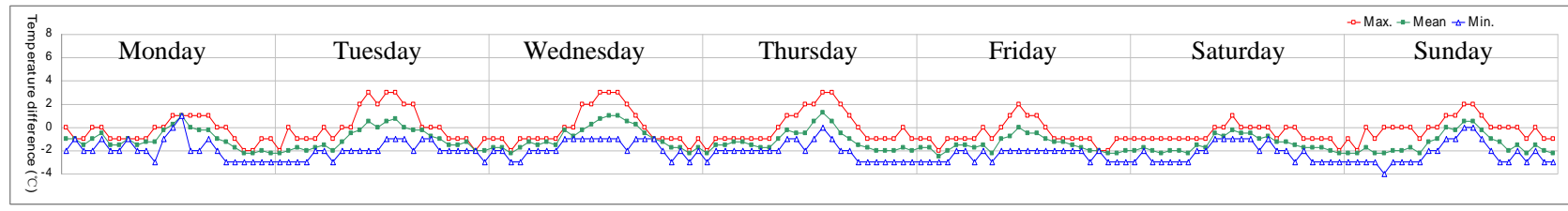

Fig. 7. The seven-day temperature difference between Daliau-Linyuan stations in weeks of January.

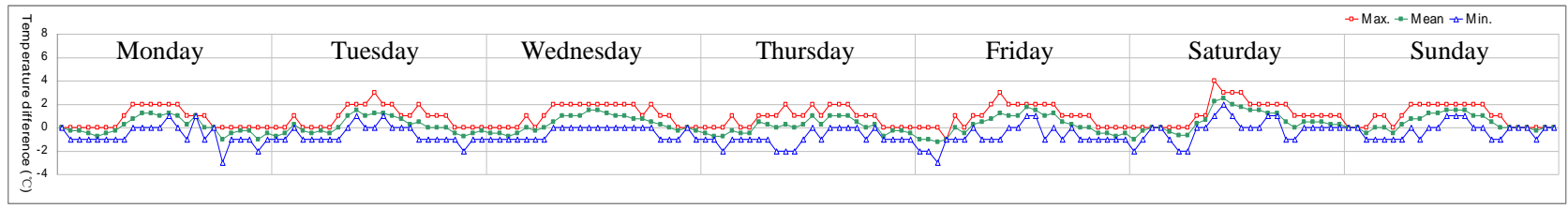

Fig. 8. The seven-day temperature difference between Daliau-Linyuan stations in weeks of July.

Judging from the peak temperature differences around or after noon in a cycle on weekdays, in addition to the consequences of stronger solar radiation, the heat discharged by air conditioners is considered crucial in warming the downtown environment. According to the daily peaks in these plots, there could be a temperature decrease by $2^{\circ} \mathrm{C}$ in downtown areas on weekends. Similar evidences of warmer weekdays are found in other cities, for example Melbourne [10], Seoul [11], and Portland [12]. Explanations of intensified heat island effect on weekdays involve higher traffic density and more carbon dioxide emissions [12]-[16].

\section{CONCLUSION AND SUGGESTION}

Results of most downtown-suburban temperature differences present temporal characteristics consistent with previous local studies, namely larger variations around noon and more obvious heat island effect in summer. On average, downtown-suburban temperature difference in January is $3.2^{\circ} \mathrm{C}$ and in July $5^{\circ} \mathrm{C}$. Despite that the influence of economic activities was obscure in the temperature difference curves plotted on a 24-hour basis, economic activities are found to be salient in explaining the observed temperature difference cycles on weekdays and the absence of these cycles on weekends. This temporal pattern of heat island effect seems to emerge more frequently in winter than in summer and is noticeable only when the temperature data of a station are contrasted with that of a baseline station.

Mass transportation systems or green vehicles are still recommended for urban traffic planning and the influence of the heat discharged from air conditioners cannot be overlooked. Future studies are suggested to examine the specific physical settings in the surroundings of the monitoring stations rather than overall conditions of the areas within which the stations locate. It is also suggested to conduct quantitative analyses that include numeric variables concerning human activities such as air conditioner density, electricity used, and traffic flow in the estimation of the intensity of heat island effect. These analyses should inform us to what extent our behaviors contribute to the unbearable hotter urban environment.

\section{ACKNOWLEDGMENT}

Y.-L. Chao would like to express his sincere gratitude to Hou-Zuo Liu, Chin-Chen Ho, and Min-Jui Chiu for their hard work in processing the data.

\section{REFERENCES}

[1] M. Santamouris, "Heat-island effect," in Energy and Climate in the Urban Built Environment, M. Santamouris, Ed., New York: Routledge, 2011, ch. 5, pp. 48-68.

[2] E. H. Landsberg, The Urban Climate, Maryland: Academic Press, 1981.

[3] T. R. Oke, G. T. Johnson, D. G. Steyn, and I. D. Watson, "Simulation of surface urban heat island," Boundary-Layer Meteorology, vol. 56, no. 4, pp. 339-358, Sep. 1991.

[4] R. Giridharan, S. S. Y. Lau, S. Ganesan, and B. Givoni, "Urban design factors influencing heat island intensity in high-rise high-density environments of Hong Kong," Building and Environment, vol. 42, no 10, pp. 3669-3684, Oct. 2007.

[5] S. K. Jusuf, N. H. Wong, E. Hagen, R. Anggoro, and Y. Hong, "The influence of land use on the urban heat island in Singapore," Habitat International, vol. 31, no. 2, pp. 232-242, Jun. 2007.

[6] Taiwan Central Weather Bureau. Climate. [Online]. Available: http://www.cwb.gov.tw/V7e/climate/\#

[7] Taiwan Environmental Protection Administration. The Air Quality Monitoring Web. [Online]. Available: http://aqm.epa.gov.tw/taqm/zh-tw/YearlyDataDownload.aspx

[8] H.-T. Lin, H.-C. Kuo, K.-P. Lee, T.-C. Chen, and K.-T. Chen, "Experimental analyses on urban heat island effect and its improvement strategies in coastal cities of Taiwan: An analysis for 
Tainan, Kaohsiung, and Hsinchu," Journal of City and Planning, vol. 28, pp. 323-341, 2001.

[9] H.-T. Lin, K.-P. Lee, K.-T. Chen, L.-J. Lin, H.-C. Kuo, and T.-C. Chen, "Experimental analyses of urban heat island effects of the four metropolitan cities in Taiwan (I)-The comparison of the heat island intensities between Taiwan and the world cities," Journal of Architecture, no. 31, pp. 51-73, Dec. 1999.

[10] I. Simmonds and K. Keay, "Weekly cycle of meteorological variations in Melbourne and the role of pollution and anthropogenic heat release," Atmospheric Environment, vol. 31, no. 11, pp. 1589-1603, Jun. 1997.

[11] Y. H. Kim and J. J. Baik, "Spatial and temporal structure of the urban heat island in Seoul," Journal of Applied Meteorology, vol. 44, no. 5, pp. 591-605, 2005.

[12] M. A. Hart and D. J. Sailor, "Quantifying the influence of land-use and surface characteristics on spatial variability in the urban heat island," Theoretical and Applied Climatology, vol. 95, no. 3-4, pp. 397-406, Mar. 2009.

[13] H. Z. Liu, J. W. Feng, L. Järvi, and T. Vesala, "Four-year (2006-2009) eddy covariance measurements of $\mathrm{CO}_{2}$ flux over an urban area in Beijing," Atmospheric Chemistry and Physics, vol. 12, pp. 7881-7892, 2012.

[14] M. García, M. L. Sánchez, and I. A. Pérez, "Synoptic weather patterns associated with carbon dioxide levels in Northern Spain," Science of the Total Environment, vol. 408, no. 16, pp. 3411-3417, Jul. 2010.
[15] S. Burri, C. Frey, E. Parlow, and R. Vogt, " $\mathrm{CO}_{2}$ fluxes and concentrations over an urban surface in Cairo/Egypt," presented at the Seventh International Conference on Urban Climate, Yokohama, Japan, June 29 - July 3, 2009.

[16] D. D. Parrish, H. B. Singh, L. Molina, and S. Madronich, "Air quality progress in North American megacities: A review," Atmospheric Environment, vol. 45, no. 39, pp. 7015-7025, Dec. 2011.

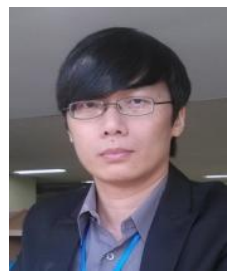

Yu-Long Chao was born in southern Taiwan in 1974 $\mathrm{He}$ received the $\mathrm{Ph} . \mathrm{D}$. degree in public affair management from National Sun Yat-sen University, Kaohsiung, Taiwan, in 2009 and the M.S. degree in environmental education from National Taiwan Normal University, Taipei, Taiwan, in 1999.

He taught earth science at a high school before serving as a coordinator at the Southern Environmental Education Regional Center, funded by Taiwan's Environmental Protection Administration. Currently he is also an adjunct assistant professor at the Department of Environmental, Safety, and Health Engineering, National Kaohsiung First University of Science and Technology. He is interested in the study of environmental education, environmental management, and science teaching.

Dr. Chao was consecutively awarded by Ministry of Education for instructing students winning prizes at high school science fairs. 